\title{
Pauses...what pauses?
}

\section{Prasad Gunaruwan, Malcolm Barlow}

Department of Cardiology, John Hunter Hospital, Newcastle, New South Wales, Australia

Correspondence to Dr Prasad Gunaruwan, gunaruwan@doctors.org.uk

\section{DESCRIPTION}

A 72-year-old woman was admitted for management of constipation secondary to opiod medications. Opiods were prescribed for pain relief following fractured humerus after a fall 1 week previously. Further history included multiple unexplained falls without syncope on the background of deforming rheumatoid arthritis osteoporosis and treated hypertension. On admission she was found to be tachycardic with atrial flutter with variable block and intermittent left bundle branch block aberrancy (figures 1 and 2). Digoxin and atenolol was started. On day 2 asymptomatic pauses up to $3.7 \mathrm{~s}$ were noted and atenolol and digoxin were ceased. On day 4, the cardiac monitor recorded the rhythm strip shown in figure 3 . The patient was asleep. Based on the multiple falls and the rhythm strip a permanent pacemaker was implanted. Following lead insertion the patient redeveloped atrial flutter shown in figure 4. The isoelectric nature of the QRS in lead II during left bundle branch block was noted. This observation led to closer examination of the prepacemaker implant rhythm strip (figure 5) showing clear regular variations in baseline consistent with an isoelectric left bundle branch block QRS complex.

This case is an example where decisions based on single limb lead cardiac monitoring led to inappropriate implantation of a permanent pacemaker.

\section{Learning points}

Always review more than one simultaneous ECG leads when analysing rhythm strips.

- As a general rule symptoms are reproduced by the arrhythmia.

- Be cautious and meticulous when assessing history of falls and syncope in the elderly.

\section{Competing interests None.}

Patient consent Obtained.

Provenance and peer review Not commissioned; externally peer reviewed.

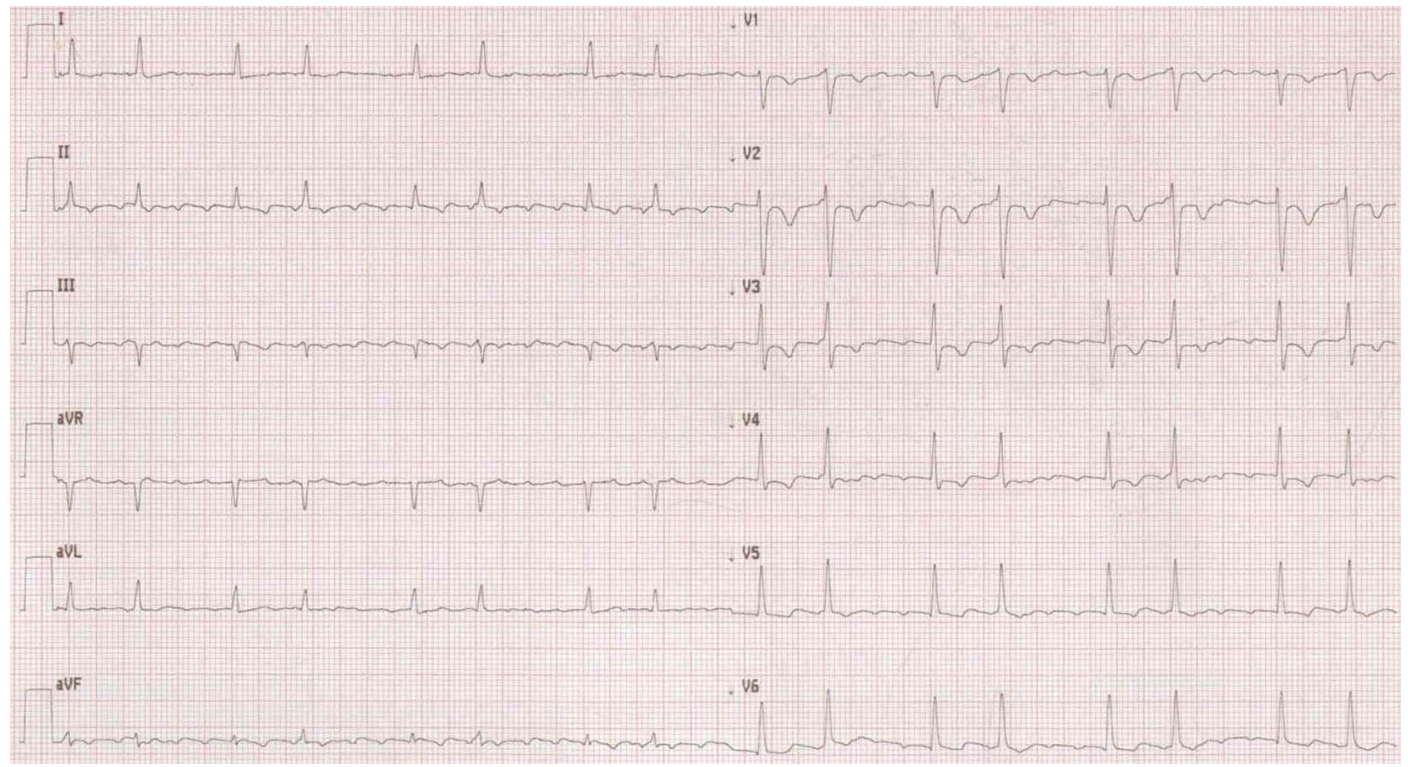

Figure 1 Atrial flutter with variable block.

To cite: Gunaruwan $P$ 


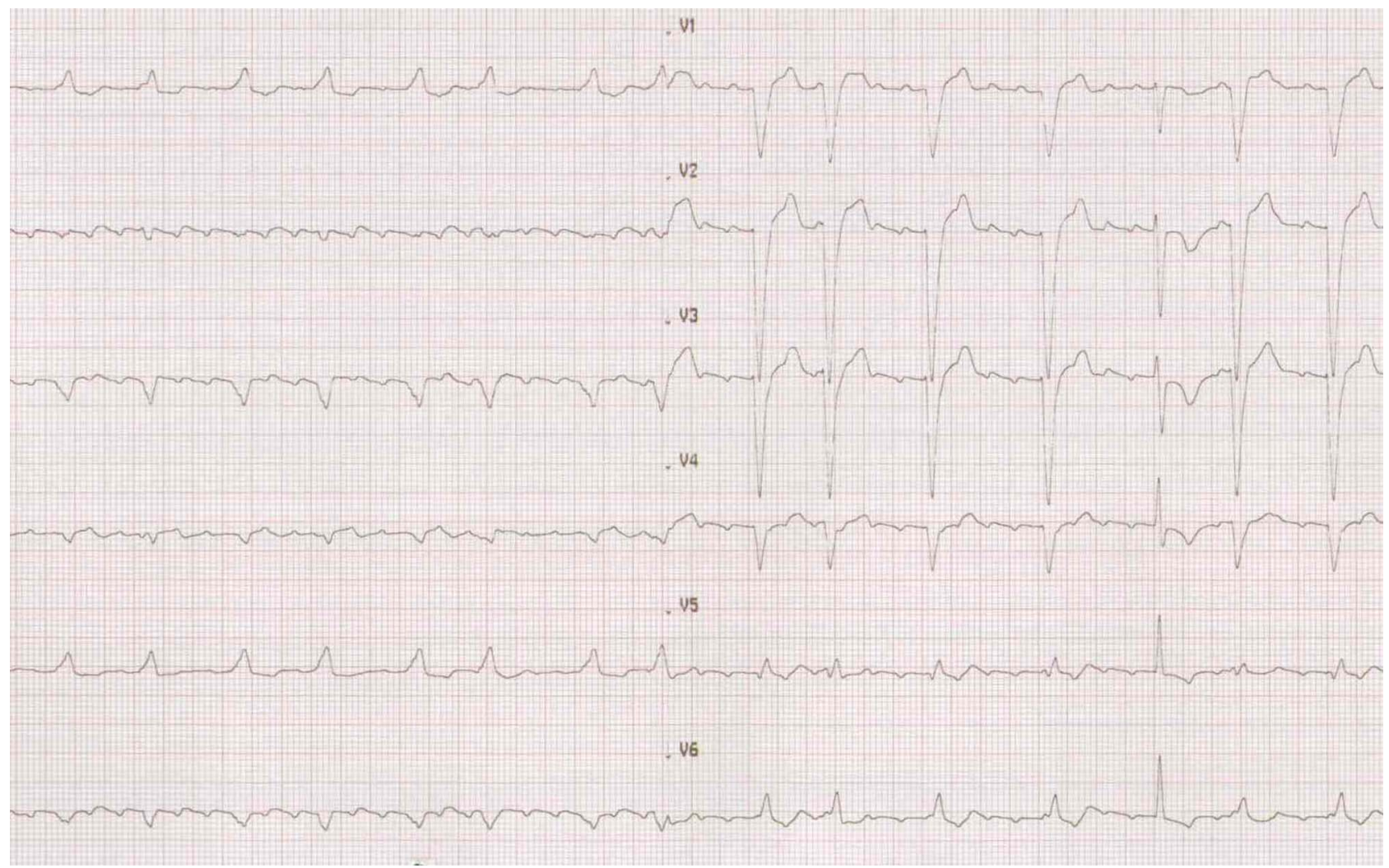

Figure 2 Atrial flutter with variable block and left bundle branch bock aberrancy.

Figure 3 Rhythm strip.

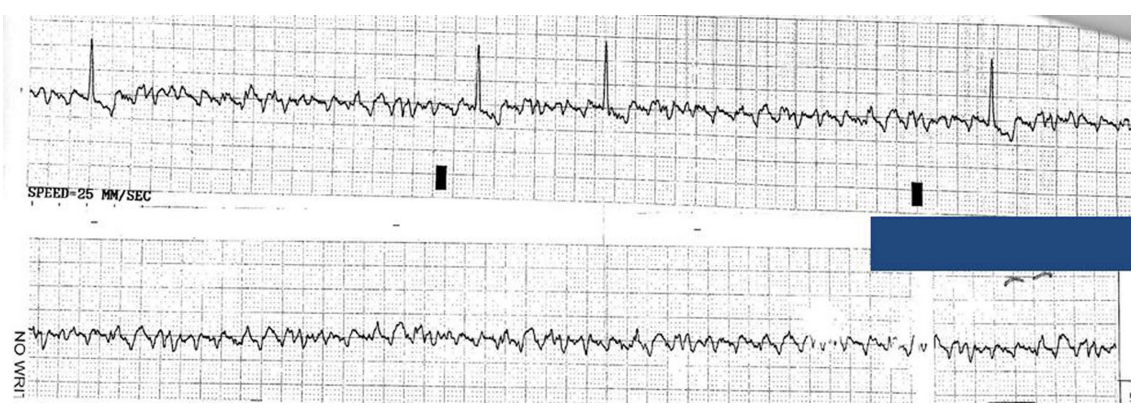

Figure 4 Atrial flutter with 2:1 block and left bundle branch block aberrancy.

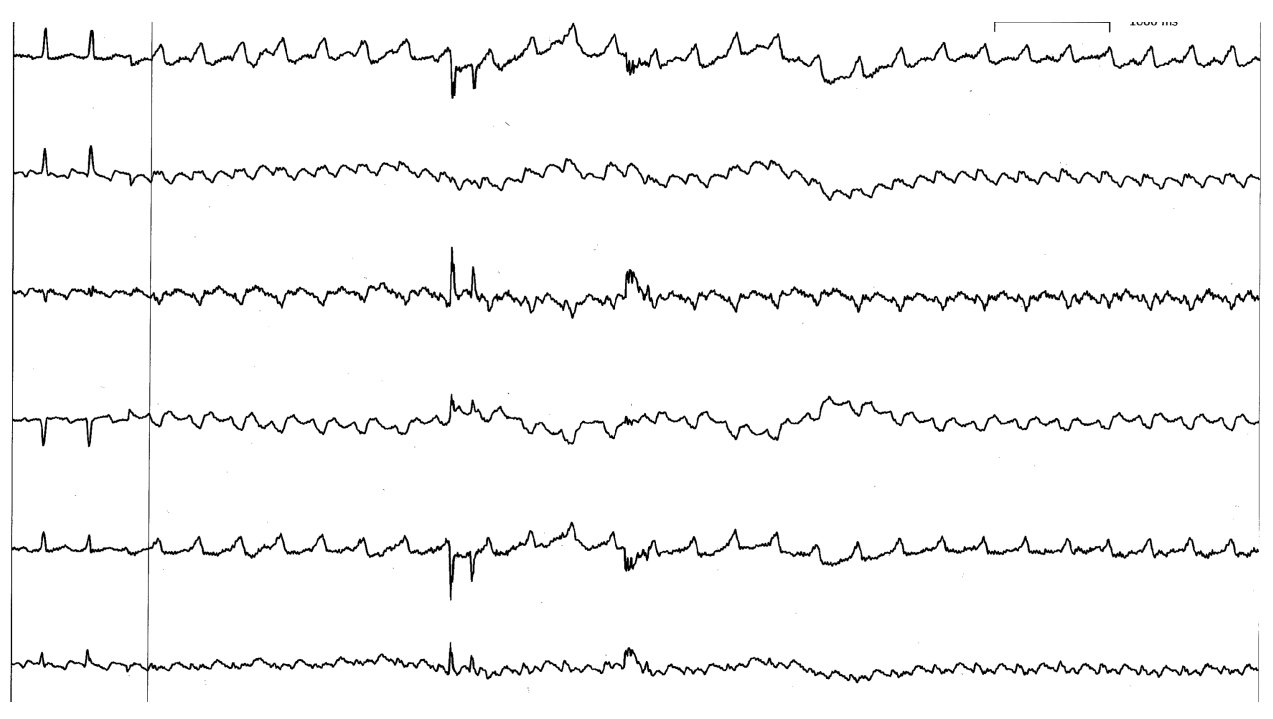




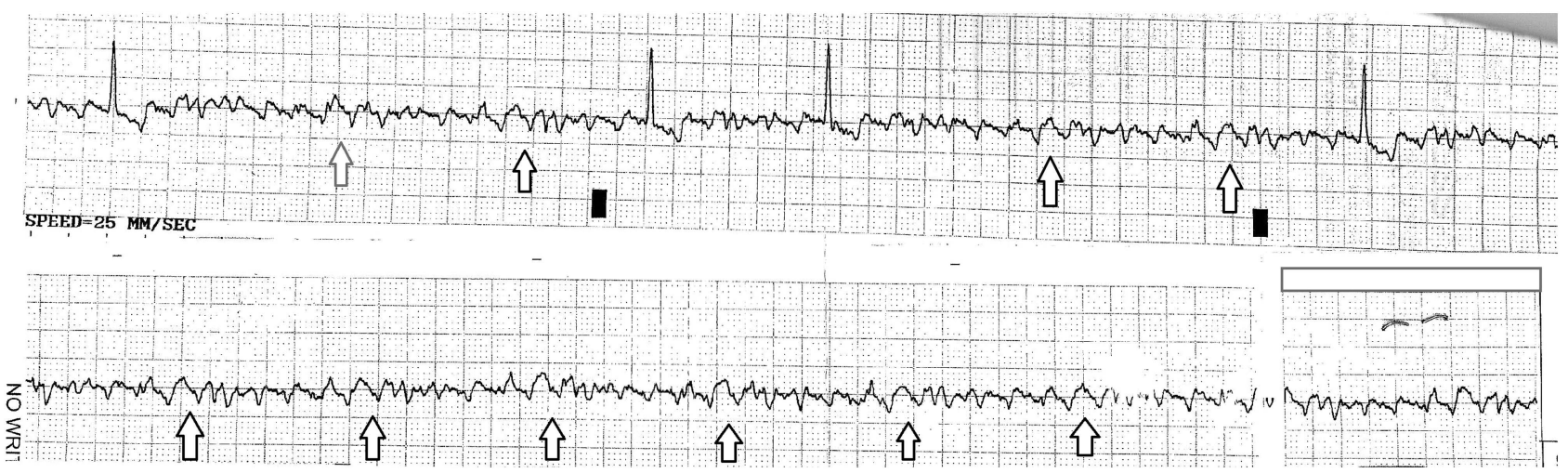

Figure 5 Rhythm strip with QRS complexes with left bundle aberrancy shown with arrows.

Copyright 2013 BMJ Publishing Group. All rights reserved. For permission to reuse any of this content visit http://group.bmj.com/group/rights-licensing/permissions.

BMJ Case Report Fellows may re-use this article for personal use and teaching without any further permission.

Become a Fellow of BMJ Case Reports today and you can:

- Submit as many cases as you like

- Enjoy fast sympathetic peer review and rapid publication of accepted articles

- Access all the published articles

- Re-use any of the published material for personal use and teaching without further permission

For information on Institutional Fellowships contact consortiasales@bmjgroup.com

Visit casereports.bmj.com for more articles like this and to become a Fellow 